\title{
(6) OPEN ACCESS \\ Integrated surgical academic training in the UK: a cross-sectional survey
}

\author{
Natalie S Blencowe, James C Glasbey, Philip J McElnay, Aneel Bhangu, Vimal J Gokani, \\ Rhiannon L Harries, on behalf of the Council of the Association of Surgeons in Training
}

Association of Surgeons in Training, Lincoln's Inn Fields, London, UK

\section{Correspondence to}

Natalie S Blencowe, Association of Surgeons in Training, Lincoln's Inn Fields, London, UK; natalie.blencowe@bristol.ac.uk

Received 10 December 2016 Revised 13 February 2017

Accepted 5 March 2017

Published Online First

13 April 2017

\section{CrossMark}

To cite: Blencowe NS,

Glasbey JC, McElnay PJ, et al. Postgrad Med J

2017:93:581-586

\section{ABSTRACT}

Objectives This study aimed to explore variations in the provision of integrated academic surgical training across the UK.

Design This is an online cross-sectional survey (consisting of 44 items with a range of free-text binomial and 5-point Likert scale responses) developed by the Association of Surgeons in Training.

Setting A self-reported survey instrument was distributed to academic surgical trainees across the UK $(n=276)$.

Participants $143(51.9 \%)$ responses were received (81\% male, median age: 34 years), spanning all UK regions and surgical specialties. Of the 143 trainees, 29 were core trainees $(20.3 \%)$, 99 were specialty trainees $(69.2 \%)$ and $15(10.5 \%)$ described themselves as research fellows.

Results The structure of academic training varied considerably, with under a third of trainees receiving guaranteed protected time for research. Despite this, however, $53.1 \%$ of the respondents reported to be satisfied with how their academic training was organised. Covering clinical duties during academic time occurred commonly (72.7\%). Although most trainees $(n=88,61.5 \%)$ met with their academic supervisor at least once a month, six (4.2\%) never had an academic supervisory meeting. Most trainees ( $n=90,62.9 \%)$ occupied a full-time rota slot and only $9.1 \%(n=13)$ described their role as 'supernumerary'. Although $58.7 \%(n=84)$ of the trainees were satisfied with their clinical competence, $37.8 \%(n=54)$ felt that clinical time focused more on service provision than the acquisition of technical skills. 58 (40.6\%) had experienced some form of negative sentiment relating to their status as an academic trainee.

Conclusions Integrated academic training presents unique challenges and opportunities within surgery. This survey has identified variation in the quality of current programmes, meaning that the future provision of integrated surgical academic training should be carefully considered.

\section{INTRODUCTION}

The 2005 Walport report commented on the 'perilous state of academic medicine...in the UK'. ${ }^{1}$ It identified that there were nearly $20 \%$ fewer clinical academics in surgery (and half the number of clinical lecturers) compared with 2000, in line with an overall decrease in the total number of clinical academics. ${ }^{2}$ Walport recommended that, in order to ensure a strong future across all fields, an integrated clinical academic training pathway should be developed (figure 1). ${ }^{13}$ To successfully obtain these posts, trainees need to demonstrate excellence (or the potential for excellence) in academic medicine and clinical abilities. The academic pathway starts at the foundation programme level, ${ }^{4}$ and during specialty training, trainees can apply for the National Institute for Health Research (NIHR)funded (originally termed 'Walport fellowships') Integrated Academic Training Programme (England), Welsh Clinical Academic Track Fellowships, ${ }^{6}$ or the Scottish Clinical Research Excellence Development Scheme. ${ }^{7}$ These posts are usually allocated to institutional partnerships of universities, National Health Service (NHS) Trusts and local education training boards (LETBs). As such, they exist in addition to the normal complement of clinical training posts and may, therefore, be seen as supernumerary to Health Education Englandfunded posts. Trainees can move competitively up the promotional ladder (and join the training pathway at any point), increasing their research productivity, funding and leadership until they are ready to apply for a formal academic role at the consultant level.

Clinical academic posts provide clinical training with protected time for research, either to assemble a successful fellowship proposal to gain research funding for a higher degree at the predoctoral level (academic clinical fellow, ACF) or to complete specialist surgical training with intercalated fulltime research experience at the postdoctoral level (clinical lecturer, CL). Guidelines state that the clinical:academic balance should be 75:25 for ACFs (for a maximum of 3 years) and 50:50 for CLs (for a maximum of 4 years). Whereas there is no perceived need for ACFs to extend their training, it is recognised that achieving Certificate of Completion of Training (CCT) is likely to be delayed for CLs. The guidelines also recommend that trainees' academic achievements are assessed during the Annual Review of Competence Progression (ARCPs), alongside clinical competencies. Anecdotally, there is significant variation in the structure and quality of clinical academic training for surgeons. This study aimed to explore variations in the provision of academic surgical training across the UK.

\section{METHODS}

A cross-sectional survey, developed by council members of the Association of Surgeons in Training (ASiT), was conducted. The questionnaire consisted of 44 items with a range of free-text, binomial and 

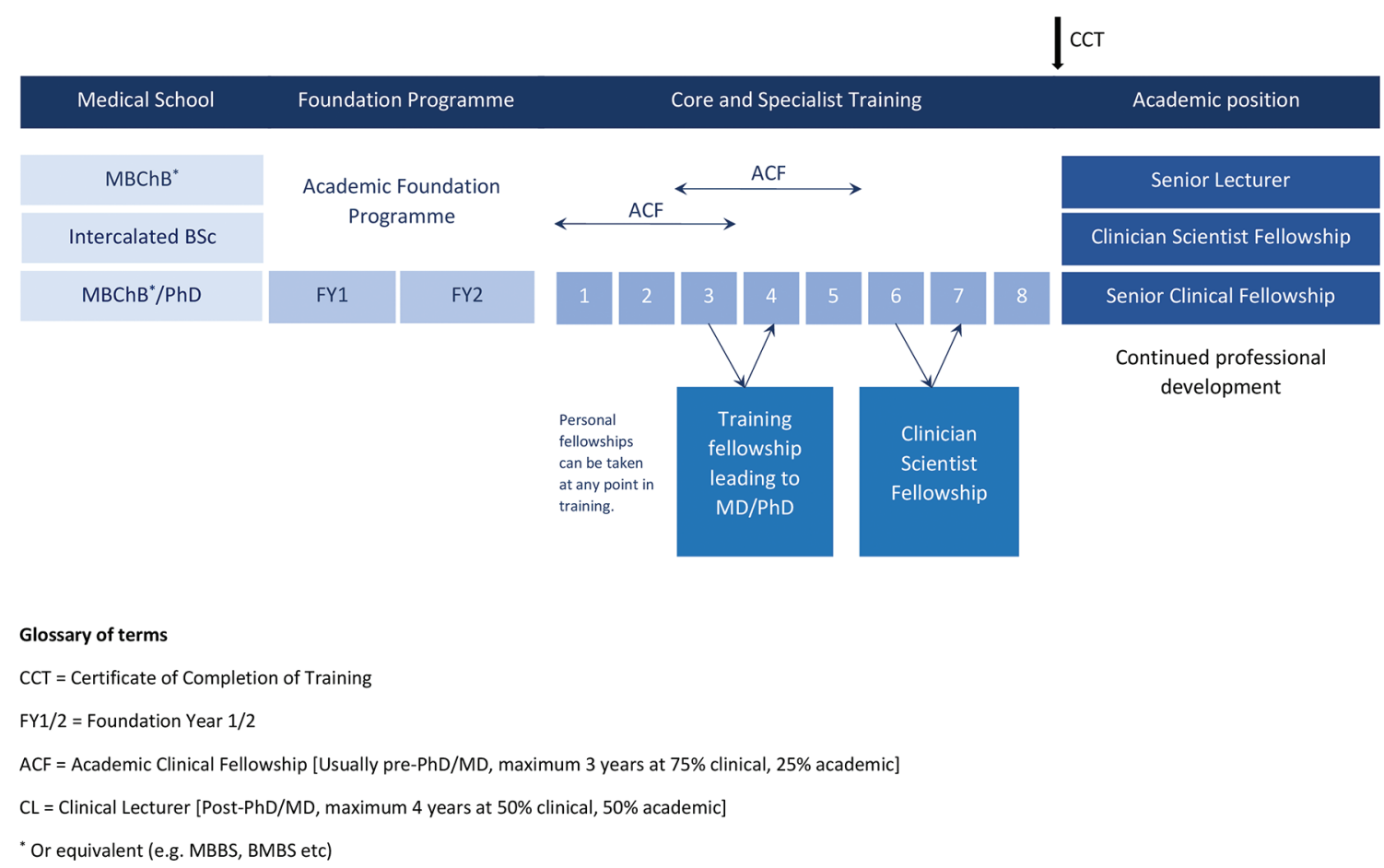

Figure 1 The National Institute for Health Research academic training pathway.

5-point Likert scale responses. Questions related to trainee and training post demographics (age, sex, location, specialty, training level, funding source), allocation of research time (amount of time and how it was decided, and whether academic time is protected), details about academic and clinical training arrangements, the ARCP process and extension of CCT dates, and others' attitudes towards academic trainees.

Each item was extensively tested and iterated before distribution to maximise content validity. The survey was distributed via an online platform to academic trainees across the UK using mailing lists from the NIHR Trainee Coordinating Centre, Joint Committee on Surgical Training (JCST), postgraduate schools and surgical societies. This was supplemented by social media advertising. Opinions were sought from academic trainees from the core trainee level (postgraduate year 3) upwards, from all surgical specialties. Foundation programme trainees were excluded.

Results were summarised using descriptive statistics, and freetext answers were categorised into broad themes to facilitate interpretation. Where appropriate, comparisons were made between training levels (eg, ACF and CL) and funding type (NIHR and non-NIHR).

\section{RESULTS}

From a total of 276 JCST-recognised academic trainees, 143 responses (51.9\%) were received from academically appointed trainees across a range of LETB regions and specialties (table 1 ). Most respondents were male (81\%) and the median age was 34 years (range: 29-55). Of the 143 trainees, 29 were core trainees (20.3\%), 99 were specialty trainees (69.2\%) and $15(10.5 \%)$ described themselves as research fellows. Eighty-five (59.4\%) were funded by the NIHR. Most had not previously held $(\mathrm{n}=55,38.5 \%)$ an academic training post, although $25.9 \%$ $(\mathrm{n}=37)$ had completed an academic foundation programme. Interview processes included local selection $(n=68,47.6 \%)$, national selection $(\mathrm{n}=36,25.2 \%)$ and a combination of the two approaches $(\mathrm{n}=37,25.9 \%)$.

\section{Academic time}

The way in which trainees' academic time was organised varied considerably: $32.9 \%(\mathrm{n}=47)$ had a formal research block, $20.3 \%$ $(\mathrm{n}=29)$ combined clinical and academic work, $18.9 \%(\mathrm{n}=27)$ fitted in around the clinical team and the rest had no fixed pattern. Most research blocks lasted between 3 and 6 months $(\mathrm{n}=34,23.8 \%)$. Of the trainees combining clinical and academic work, $17.6 \%(\mathrm{n}=18)$ had no dedicated academic days. Most trainees $(n=85,59.4 \%)$ reported having some input into the allocation of their academic time, although only 22 of the NIHR trainees $(29.5 \%)$ received this flexibility. Free-text comments suggested that the allocation of academic time varied between training regions, specialties and whether the post was considered a job share or supernumerary. Overall, many trainees were satisfied or very satisfied with the way their academic time was organised $(n=76,53.1 \%)$, with $17.5 \%(n=25)$ dissatisfied.

Only $29.2 \%$ (30.6\% of NIHR trainees) routinely received protected academic time and $72.7 \%$ (61.2\% of NIHR trainees) had been asked to cover clinical duties during academic time (figure 2).

\section{Academic supervision and training}

Although most trainees $(n=88,61.5 \%)$ met with their academic supervisor at least once a month (67.1\% of NIHR trainees), six (4.2\%) had never had an academic supervisory meeting $(4.7 \%$ of NIHR trainees). Twenty-four (19.8\%) had a single consultant who acted as their clinical, educational and academic supervisor. Overall, there was positive reflection on the quality (mean rating: 4.0/5) and frequency (mean rating: 3.9/5) of academic supervision.

Seventy-four $(51.7 \%)$ did not have access to any form of research skills training programmes. This was similar among 


\begin{tabular}{|c|c|c|}
\hline Characteristics & & $\begin{array}{c}\text { Trainees, } \\
\mathrm{n}=143(\%)\end{array}$ \\
\hline \multirow[t]{5}{*}{ Training post } & ACF (ST1 entry) & $37(25.9)$ \\
\hline & ACF (ST3+ entry) & $23(16.1)$ \\
\hline & ACF (other entry) & $14(9.8)$ \\
\hline & $\mathrm{CL}$ & $53(37.1)$ \\
\hline & Other* & $16(11.2)$ \\
\hline \multirow[t]{2}{*}{ Type of funding } & NIHR & $85(59.4)$ \\
\hline & Other & $58(40.6)$ \\
\hline \multirow[t]{10}{*}{ Specialty } & Cardiothoracic & $10(7.0)$ \\
\hline & General surgery & $51(35.7)$ \\
\hline & Neurosurgery & $11(7.7)$ \\
\hline & Otolaryngology & $11(7.7)$ \\
\hline & Oral and maxillofacial & $4(2.8)$ \\
\hline & Paediatric surgery & $4(2.8)$ \\
\hline & Plastic surgery & $9(6.3)$ \\
\hline & Trauma and orthopaedics & $21(14.7)$ \\
\hline & Urology & $14(9.8)$ \\
\hline & Vascular & $6(4.2)$ \\
\hline \multirow[t]{4}{*}{ Main type of research } & Basic sciences & $32(22.4)$ \\
\hline & Translational & $47(32.9)$ \\
\hline & Clinical & $40(28.0)$ \\
\hline & Other & $2(1.4)$ \\
\hline \multirow[t]{16}{*}{ Training region } & East Midlands & $11(7.7)$ \\
\hline & East of England & $14(9.8)$ \\
\hline & KSS & $0(0)$ \\
\hline & London & $29(20.3)$ \\
\hline & Mersey & $2(1.4)$ \\
\hline & North East & $7(4.9)$ \\
\hline & North West & $3(2.1)$ \\
\hline & Northern Ireland & $3(2.1)$ \\
\hline & Peninsula & $1(0.7)$ \\
\hline & Severn & $6(4.2)$ \\
\hline & Scotland & $17(11.9)$ \\
\hline & Thames Valley & $16(11.2)$ \\
\hline & Wales & $3(2.1)$ \\
\hline & Wessex & $8(5.6)$ \\
\hline & West Midlands & $13(9.1)$ \\
\hline & Yorkshire \& Humber & $10(7.0)$ \\
\hline \multirow[t]{2}{*}{ Type of training $\dagger$} & Full-time & $138(96.5)$ \\
\hline & Less than full-time & $4(2.8)$ \\
\hline \multirow{2}{*}{$\begin{array}{l}\text { Previously held academic } \\
\text { post? }\end{array}$} & Yes & $89(62.2)$ \\
\hline & No & $54(37.8)$ \\
\hline
\end{tabular}

*Including roles such as postdoctoral fellowships and clinician scientists. tOne response missing.

ACF, academic clinical fellow; CL, clinical lecturer; KSS, Kent, Surrey, Sussex; NIHR, National Institute for Health Research; ST, specialty trainee.

NIHR $(n=44,51.8 \%)$ trainees. Although some trainees $(n=62$, $42.4 \%$ ) reported access to financial support (outwith LETB study budgets) for activities such as conference presentations, this was mostly from dedicated NIHR training allowances $(n=61)$. Thirty-one $(21.7 \%)$ received no additional funding and 19 (13.3\%) sought their own.

\section{Clinical training}

Most trainees ( $n=90,62.9 \%)$ occupied a full-time rota slot (74.1\% of NIHR trainees, $n=63)$. Only 9.1\% $(n=13)$ described their role as 'supernumerary' $(9.4 \%$ of NIHR trainees, $n=8)$.
Job sharing with other academic trainees $(n=8,5.6 \%)$ or less than full-time trainees $(n=2,1.4 \%)$ was uncommon. Ninety-four $(65.7 \%)$ undertook $100 \%$ of the on-call rota (ie, the usual proportion undertaken by non-academic trainees), with $7.0 \%(n=12)$ and $0.7 \%(n=1)$ undertaking $50 \%$ and $75 \%$, respectively. Of the trainees undertaking $100 \%$, many $(n=53$, $58.9 \%$ ) reported that they had no choice about this arrangement. Thirty-three (36.7\%) stated that it helped maintain their salary, and $37(41.1 \%)$ stated it helped gain emergency experience. Some trainees reported that a $100 \%$ on-call slot was 'not compatible with academic training', but despite this, experienced difficulties in negotiating different arrangements. Of the trainees undertaking less than $100 \%$ on-call, some did this to protect their research time, whereas others were unable to occupy a full slot due to the lack of availability.

Most commonly, clinical training arrangements were made by LETBs or clinical teams $(n=68,47.6 \%)$ rather than the trainees themselves $(n=40,28.0 \%)$. Fifty-two $(36.3 \%)$ of the trainees (38.8\% of NIHR trainees, $\mathrm{n}=33$ ) reported that their training programme director discussed the suitability of clinical posts for academic trainees, prior to placement allocations.

Although 58.7\% $(n=84)$ of trainees were satisfied with their clinical competence (35 CLs, 66.0\%; 13ST3+ ACFs, 56.5\%; 19ST1+ ACFs, 51.4\%; 57 NIHR trainees, 67.1\%), 37.8\% $(n=54)$ felt that clinical time focused more on service provision than the acquisition of technical skills (20 CLs, 37.7\%; 14 ST3+ ACFs, 60.9\%; 14ST1+ ACFs, 37.8\%; 35 NIHR trainees, $41.2 \%)$.

\section{ARCP and CCT}

Seventy-three $(51.0 \%)$ of trainees underwent a single ARCP to review both clinical and academic progress, whereas 25 (17.5\%) had a dedicated academic ARCP, separate from their clinical ARCP. Sixteen (11.2\%) of trainees reported that their academic progress had not been formally reviewed. Fifty-two $(36.4 \%)$ of trainees were indifferent about the usefulness of the academic ARCP and 42 (29.4\%) found it an unhelpful process. Free-text comments are provided in table 2. Twenty-seven (18.9\%) of trainees had already amended their CCT date due to difficulties in achieving clinical competencies. This was more common among NIHR $(\mathrm{n}=21,24.7 \%)$ and senior trainees (10 CLs, 37.0\% and 7 ST3 + ACFs, 25.9\%) than ST1+ ACFs $(n=8,29.6 \%)$.

\section{Attitudes towards academic trainees}

In the clinical workplace, less than half of the respondents $(n=72,50.3 \%)$ felt that they were given equal opportunities when compared with their non-academic colleagues, including operative training (figure 3). Fifty-eight (40.6\%) had experienced some form of negative sentiment relating to their status as an academic trainee. Of these, $13(22.4 \%)$ were female and more were senior (23 CLs, 39.7\% and $15 \mathrm{ST} 3+\mathrm{ACFs}, 25.9 \%$ ) than junior (15ST1+ ACFs, 25.9\%).

\section{DISCUSSION}

This UK-wide survey of 143 academic surgical trainees, only 27 of whom were female $(18.8 \%)$, found wide variation in the structure and perceived quality of training. Although less than a third of trainees received guaranteed protected time for research and $77.4 \%$ had covered clinical duties during academic time, $53.1 \%$ of the respondents reported to be satisfied with how their academic training was organised. Trainees reported a lack of flexibility regarding on-call arrangements, occupying a full-time rota slot despite having a 'less than 100\%' clinical contract. Although 


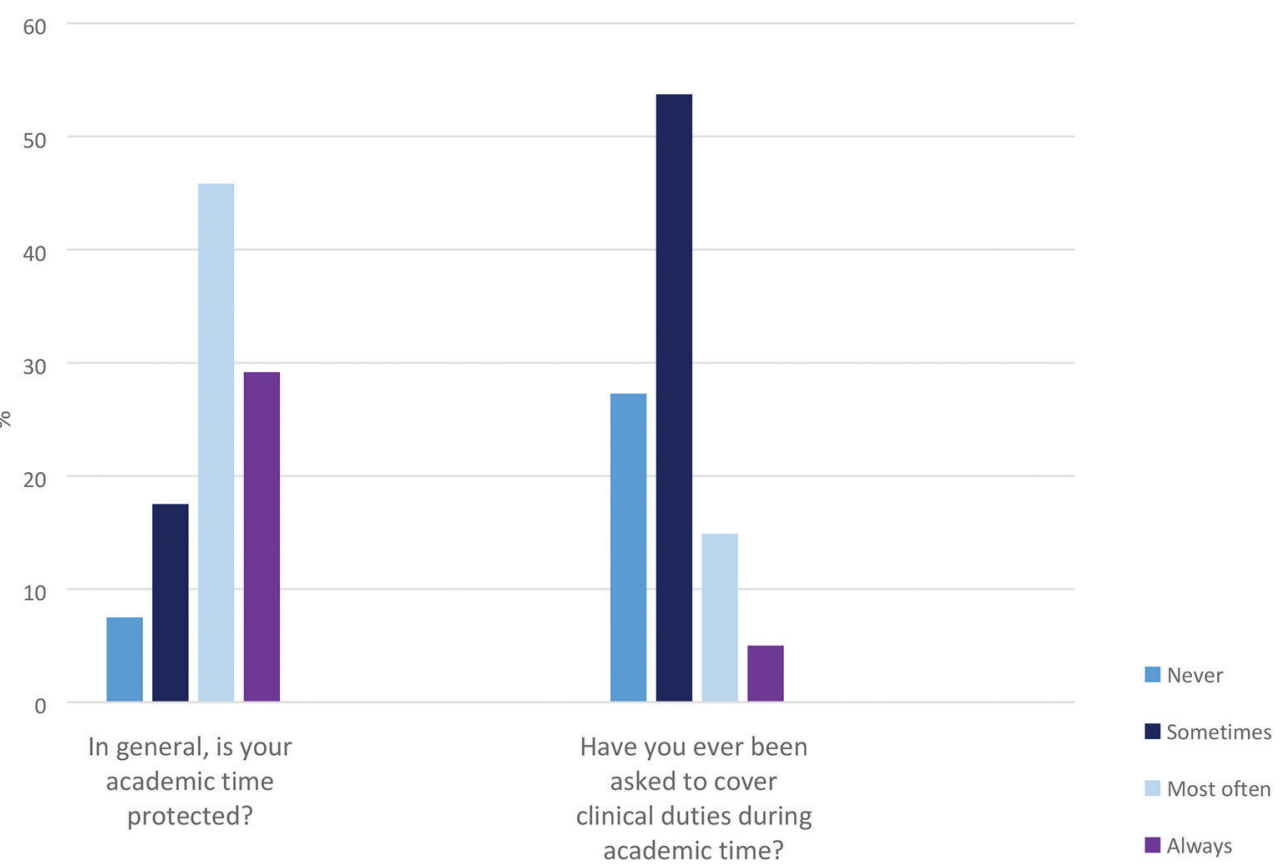

Figure 2 Protection of academic time.

the NIHR recommends that academic trainees are allocated a supernumerary role, only $9.4 \%$ of trainees reported this. Most trainees' academic progress was formally reviewed in some way; however, $35 \%$ did not perceive this to be a useful process. In the clinical workplace, approximately half of trainees felt that they were given equal opportunities to non-academic colleagues and were satisfied with their clinical competence. However, negative sentiments (including bullying and undermining) relating to their status as an academic trainee were common. The main difference between NIHR and non-NIHR trainees was input into the allocation of their academic time, with only $29.5 \%$ of the NIHR trainees $(29.5 \%)$ receiving this flexibility compared with $59.4 \%$ overall. There are, therefore, several areas that require improvement in order to maximise training opportunities and satisfaction among academic surgical trainees.
The General Medical Council (GMC) requires trainees of all specialties to complete an annual national training survey. In 2014, an academic training subreport was produced, although this did not provide separate data for surgical trainees. ${ }^{8}$ Although the GMC survey contained over 1000 responses, proportions of participating ACF-level and CL-level trainees were similar. Of the trainees, 66\% (GMC) and 29\% (ASiT) reported their academic time to be consistently protected, indicating an increased service focus within surgical specialties. In terms of formal research training, 15\% (GMC) and 61\% (ASiT) did not have access to this resource, which is surprising as the NIHR provides ACFs with $£ 4500$ to use for research training. Although the proportions of trainees receiving a formal assessment of their academic progress were similar (85\% GMC, 86\% ASiT), the process was perceived as unhelpful by $12 \%(\mathrm{GMC})$ and $35 \%$ (ASiT). Of the trainees

Table 2 Comments about the academic ARCP process

\begin{tabular}{|c|c|c|}
\hline Positive & Neutral & Negative \\
\hline & $\begin{array}{l}\text { Although the ARCP was never useful in relation to my } \\
\text { academic progress, it has provided weight to negotiations } \\
\text { with trusts about when to take research time and how } \\
\text { much. }\end{array}$ & $\begin{array}{l}\text { No attention was really paid to the academic aspect of my } \\
\text { training year. }\end{array}$ \\
\hline & More useful was my review with my supervisors. & $\begin{array}{l}\text { Degrading and demoralising, no understanding of either } \\
\text { academic training or personal circumstances. }\end{array}$ \\
\hline & & They just ticked academic progress off. Focus on clinical. \\
\hline & & Simply concentrated on my clinical progress \\
\hline
\end{tabular}

ACF, academic clinical fellow; ARCP, Annual Review of Competence Progression. 


\section{Survey questions}

I have had difficulties embedding myself into the clinical team

\section{Responses}

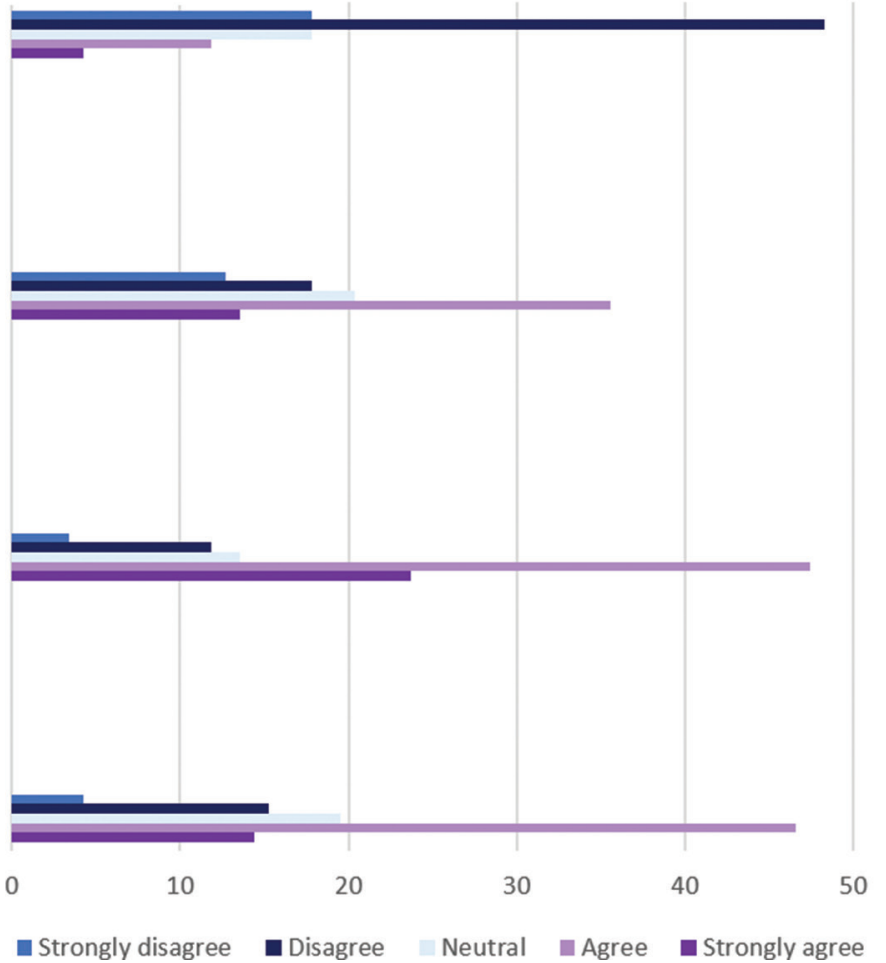

completing the GMC survey, 61\% reported academic supervision meetings at least monthly (60\% ASiT), with only $3 \%(4 \%$ ASiT) unassigned a supervisor. Overall, academic training was rated more favourably in the GMC survey, perhaps reflecting the inherent complexities associated with combining research and clinical training within craft specialties such as surgery.

The main challenges facing surgical academic trainees are to remain up-to-date, develop new technical skills and undertake the numbers of index procedures required by specialty advisory committees. Unfortunately, similar issues exist at the consultant level. In some specialties, individual surgeon outcome data (usually mortality rates) are published. ${ }^{9-11}$ Although these figures may be imprecise, particularly if based on a small number of operations (which may be the case for less-than-full-time surgeons, including academics), they are publicly available and widely scrutinised. This, plus the aforementioned challenges, may partially explain why there are less than half the amount of academics in surgery compared with medicine. ${ }^{12}$ Of particular concern is that only $19 \%$ of survey respondents were female, in keeping with the total proportion of female NIHR academic surgical trainees (CL: $n=15,13.6 \%$; ACF: $n=82,25.6 \%$ ) (Personal communication, National Institute for Health Research Trainee Coordinating Centre, 10 Feb 2017). Moreover, recent research has suggested that academic careers are considered unappealing to medical students. ${ }^{13}$ Together with the results of the current survey (and the wider GMC data), these suggest a significant gender bias. Improvements in academic training (and the perception of academic training) are, therefore, urgently required.

This national survey achieved a good response rate from academic surgical trainees across different specialties, regions and training levels. Despite this, there are several limitations that must be considered when interpreting the results. Surveys are naturally restricted by the nature of returned data and that responses among non-respondents may have been different from those of respondents. It is possible that the non-respondents were satisfied with their training and did not feel compelled to reply, or conversely were disengaged due to training problems. To facilitate analysis, the survey contained mainly closed questions, which may have restricted the depth and breadth of data obtained, for example, details about the selection processes and non-NIHR posts. Another potential limitation is that although foundation doctors were excluded, the survey included academic surgical trainees of all grades and funding sources. The rationale for this was twofold: to account for the relatively small numbers of academic surgical trainees and to increase the generalisability of study findings. We acknowledge, however, that this heterogeneity may have compromised the study's specificity and led to difficulties in interpreting the data. It is reassuring, however, that findings were similar between NIHR-funded and non-NIHR-funded trainees. Finally, responses were not collected from non-academic trainees, meaning that comparisons relating to the clinical aspects of training could not be undertaken.

A major problem for clinical academics splitting their time between NHS and academic responsibilities is that they are judged against the standard of their full-time peers in both hospital and university settings. Integrated academic training presents unique challenges and opportunities within surgery, and we have demonstrated variations in both the quality and structure of current programmes. Although variation in structure is not necessarily negative and may reflect specific requirements relating to training level or specialty, future provision of integrated surgical academic training can undoubtedly be improved. We recommend the development of clearer guidance on balancing clinical and academic training (including the role of supernumerary posts) and reviewing trainees' academic progress, 
safeguards to ensure academic time is appropriately protected, and strategies to encourage underrepresented trainee groups (eg, females) to consider academic career pathways.

\section{Strengths and limitations of the study}

- There was an excellent response rate from trainees representing a range of training levels and surgical specialties.

- Surveys are naturally restricted by the nature of returned data: therefore, responses among non-respondents may have been different from those of respondents.

- To facilitate analysis, the survey contained mainly closed questions, which may have restricted the depth and breadth of data obtained; however, this was partially mitigated by providing free-text space wherever possible.

- Responses were not collected from non-academic trainees, meaning that comparisons relating to the clinical aspects of training could not be undertaken.

\section{Main messages}

The structure of academic surgical training varies considerably. Less than a third of academic trainees in surgery receive guaranteed protected time for academic work, and $77 \%$ have covered clinical duties during academic time,

- Only $11 \%$ of trainees had 'supernumerary' roles (which are recommended by the National Institute for Health Research).

- Forty per cent had experienced negative sentiments relating to their status as an academic trainee.

\section{Current research questions}

To what extent should we standardise the delivery of academic training in surgery?

- Is there any evidence that academic surgical trainees have poorer technical skills when compared with non-academic trainees?

- How can we improve attitudes towards academic trainees in surgery?

- How can we encourage more female surgical trainees to pursue academic careers?

Contributors NB: Designed the survey, analysed the results and wrote the first draft of the mansucript. JCG: Designed the survey and coordinated dissemination, and contributed to analysis and manuscript revisions. PE: Designed the survey and contributed to manuscript revisions. AB: Designed the survey and contributed to manuscript revisions. VG: Designed the survey and contributed to manuscript revisions. RH: Designed the survey, and contributed to analysis and manuscript revisions. All authors approved the final version.

Competing interests None declared.

Provenance and peer review Not commissioned; externally peer reviewed.

Data sharing statement We have not made our data available due to the anonymity assured to the survey respondents.

Open Access This is an Open Access article distributed in accordance with the Creative Commons Attribution Non Commercial (CC BY-NC 4.0) license, which permits others to distribute, remix, adapt, build upon this work non-commercially, and license their derivative works on different terms, provided the original work is properly cited and the use is non-commercial. See: http://creativecommons.org/ licenses/by-nc/4.0/

(c) Article author(s) (or their employer(s) unless otherwise stated in the text of the article) 2017. All rights reserved. No commercial use is permitted unless otherwise expressly granted.

\section{REFERENCES}

1 UK Clinical Research Collaboration. Medically- and dentally-qualified academic staff: Recommendations for training the researchers and educators of the future. London: Modernising Medical Careers, 2005. http://www.ukcrc.org/wp-content/uploads/2014/ 03/Medically_and_Dentally-qualified_Academic_Staff_Report.pdf (accessed Jun 2016).

2 Fitzpatrick S. A survey of staffing levels of medical clinical academics in UK medical schools as at 31 July 2011, a report by the medical schools council. London: Medical Schools Council, 2012. www.medschools.ac.uk/Publications/Documents/MSC_ Clinical_Academic_Staff_Survey_310711.pdf (accessed Jun 2016).

3 Donaldson L, Bedi R, Campbell H, Wilson D, Armstrong M, Watkins R. 2005. Report of the Academic Careers Sub-Committee of MMC and the UKCRC.

4 Academic Foundation Programmes. Birmingham: The Foundation Programme. http:// www.foundationprogramme.nhs.uk/pages/academic-programmes

5 NIHR Integrated Academic Training Programme for Doctors and Dentists. London: NIHR Integrated Academic Training Pathway. http://www.nihr.ac.uk/fundingand-support/funding-for-training-and-career-development/training-programmes/ integrated-academic-training-programme/

6 Welsh Clinical Academic Track Fellowships. https://www.walesdeanery.org/specialtytraining/academic-medicine/wcat

7 Scottish Medical Training. The Scottish Clinical Research Excellence Development Scheme (SCREDS). http://www.scotmt.scot.nhs.uk/specialty/scottish-academictraining-(screds).aspx

8 National Training Survey Academic Reports. General medical council. 2014 http:// www.gmc-uk.org/NTS_2014_Academic_report.pdf_58923338.pdf

9 Association of Upper GI Surgeons of Great Britain and Ireland. Outcome data. 2016. http://www.augis.org/outcomes-data-2016/

10 Association of Coloproctology of Great Britain and Ireland. Individual surgical outcomes for 2015. http://www.acpgbi.org.uk/surgeon-outcomes/

11 Society for Cardiothoracic Surgery in Great Britain and Ireland. UK surgeons. http:// scts.org/modules/surgeons/default.aspx

12 Jacques $H$. Reduction in medical academics threatens medical education. BMJ Careers 2011. http://careers.bmj.com/careers/advice/view-article.html?id= 20003083

13 Mulla S, Watmough S, Waddelove C. Medical students' views and understanding of a career in academic medicine. Br J Hosp Med 2012;73:401-5. 